\title{
Metoclopramide: A Safe Alternative to Domperidone? A Case Report on Severe Cardiac Adverse Effects in an Older Patient
}

\author{
Laura C. Sijtsma ${ }^{1}$ - Carolina J. P. W. Keijsers ${ }^{1}$ - Angèle P. M. Kerckhoffs ${ }^{1}$ - Willem R. P. Agema ${ }^{2}$. Janet E. M. Bootsma ${ }^{1}$
}

Published online: 7 August 2018

(c) The Author(s) 2018

\begin{abstract}
Peripheral antidopaminergic medication is frequently prescribed to treat nausea. However, domperidone is ill-famed for its severe cardiac adverse effects. Metoclopramide has been suggested as a relatively safe alternative because it has long been considered to have less significant cardiovascular adverse effects. We present an older patient who developed severe bradycardia and hypotension shortly after receiving intravenous metoclopramide. Cardiac adverse effects of metoclopramide in elderly are not frequently described in the literature, especially not in patients without a major history of cardiac disease. We recommend caution with intravenous administered metoclopramide in older patients.
\end{abstract}

\section{Key Points}

Metoclopramide is generally considered a safe alternative for domperidone.

Our patient developed severe cardiac adverse effects after intravenous metoclopramide.

Be aware of cardiac adverse effects in elderly treated with intravenous metoclopramide.

\section{Introduction}

Peripheral antidopaminergic medication is frequently prescribed to treat nausea [1]. However, older patients are more prone to experiencing adverse effects in general [2]. Domperidone, a well-known antidopaminergic antiemetic drug, had its over-the-counter status withdrawn in many European countries after the European Medicines Agency

Carolina J. P. W. Keijsers

k.keijsers@jbz.nl

$\triangle$ Janet E. M. Bootsma

j.bootsma@jbz.nl

1 Department of Geriatric Medicine, Jeroen Bosch Hospital, PO Box 90153, 5200 ME 's Hertogenbosch, The Netherlands

2 Department of Cardiology, Jeroen Bosch Hospital, 's Hertogenbosch, The Netherlands
(EMA) recommended restriction of its use because of potentially life-threatening cardiac effects [3], a higher risk for which was observed in patients older than 60 years. Metoclopramide has been suggested as a relative safe alternative. The Summary of Product Characteristics (SmPC) mentions extrapyramidal disorders, akathisia, somnolence, depression, hypotension and diarrhoea as common adverse effects [4]. We report a case of severe bradycardia and hypotension in a patient after receiving intravenously administered metoclopramide.

\section{Case}

An 83-year-old female was sent to the emergency room because of persistent nausea, vomiting and weight loss of $5 \mathrm{~kg}$ in 1 month. Analyses of the nausea by abdominal ultrasound, thoracal and abdominal computed tomography (CT) scan and gastroscopy did not provide an explanation for her symptoms. Her medical history included hypertension, osteoarthritis and depressive disorder, and her cardiac history consisted of supraventricular extrasystoles and mild hypertension. Her kidney function and serum electrolytes were normal. She took perindopril $2 \mathrm{mg}$ once a day, mirtazapine $10 \mathrm{mg}$ once a day, acetaminophen $500 \mathrm{mg}$ three times a day and temazepam $10 \mathrm{mg}$ once a day. A routine electrocardiogram (ECG) showed normal sinus rhythm with a frequency of 72 beats per min (bpm) without conduction disorders. Because of severe nausea, she received $10 \mathrm{mg}$ of metoclopramide intravenously. The rate of injection was not 
registered, but we assume a slow speed (over at least $3 \mathrm{~min}$ ) in accordance with the hospital protocol. Shortly afterwards, she turned pale, started transpiring and became briefly unconscious. The heart monitor showed a bradycardia of $40 \mathrm{bpm}$ and blood pressure of $69 / 44 \mathrm{mmHg}$. A second ECG was performed at that time, $15 \mathrm{~min}$ after the first ECG, and showed a nodal escape rhythm with retrograde atrial activation with normal QRS and QT duration. She was immediately given intravenous sodium chloride $(0.9 \%)$ and her heart rate and blood pressure normalised within $20 \mathrm{~min}$. A rechallenge with metoclopramide was not performed. The severity of the adverse drug reaction was rated as severe (level 5) on the Modified Hartwig and Siegel Severity Assessment Scale. According to the preventability assessment using the Schumock scale, the adverse drug reaction was rated as unpreventable.

\section{Discussion}

In this case, the patient developed a bradycardia and severe hypotension shortly after receiving intravenous metoclopramide. No other drugs had been administered during her stay at the emergency ward. Based on the Naranjo Adverse Drug Reaction Probability Scale, these symptoms can be classified as a probable adverse drug reaction [5]. Although mirtazepine can in theory also cause cardiac adverse effects, it is highly unlikely that a drug used long-term would cause this adverse event over a drug administrated minutes before the event. A number of case reports have been published about cardiac adverse effects of metoclopramide, including hypotension, arrhythmias and cardiac arrest [6,7]. However, most older patients presented in these case reports had a history of major cardiac disease, whereas the cardiac history of our patient was limited to supraventricular extrasystoles and mild hypertension. The SmPC mentions serious cardiovascular adverse effects, including circulatory collapse, severe bradycardia, cardiac arrest and QT prolongation, particularly after intravenous administration to elderly and in patients with a cardiac history. Bradycardia is reported in the SmPC as an "uncommon side-effect" and hypotension as "common". The incidence of adverse effects such as cardiac arrest, atrioventricular block and torsade de pointes is described as "unknown" [4]. Several case reports describing-often serious-cardiovascular adverse events have been published [6,7]. We hypothesise that the incidence of adverse effects in the real clinical setting might be higher, as it is generally known that the incidence of adverse effects in registration trials differ from the real clinical setting and are often on the lower bound. This especially applies for elderly since they are usually underrepresented in trials, and those that are included are more healthy than elderly in the real practice.

The mechanism underlying the cardiac adverse effects of metoclopramide is unknown, but may be multifactorial [6]. Several potential mechanisms may be involved:

(a) Metoclopramide is a procainamide derivative and structurally related to procainamide. Metoclopramide differs from procainamide by only a 2,5 aryl substitution. It is a class Ia antiarrhythmic drug, and may therefore cause prolongation of atrioventricular conduction [8] with subsequent arrhythmias (such as bradycardia) and hypotension [9].

(b) Another possible mechanism is blockade of presynaptic autoreceptors, enhanced catecholamine release and their influence on the cholinergic system. Metoclopramide is a muscarinic acetylcholine receptor $\mathrm{M}_{1}$ agonist and an acetylcholinesterase inhibitor. The muscarinic acetylcholine receptor mediates various cellular responses, including modulation of potassium channels through the action of $\mathrm{G}$ proteins. Metoclopramide is known for influencing vasopressin secretion, probably mediated by cholinergic stimulation, resulting in bradycardia. It is hypothesised that the change of cholinergic tone has an effect on the heart by mimicking vagal stimulation.

(c) Another potential mechanism for cardiac adverse effects of metoclopramide is serotonin 5- $\mathrm{HT}_{3}$ antagonism or 5- $\mathrm{HT}_{4}$ agonism. 5- $\mathrm{HT}_{3}$ antagonism could trigger serotonin-induced bradycardia and hypotension (Bezold-Jarish reflex) [10]. Given the fact that our patient experienced bradycardia and hypotension, both of these mechanisms may be applicable in this case. Metoclopramide is a $D_{2}$ receptor antagonist and inhibits the steroid $17-\alpha$-monooxygenase activity. Metoclopramide has been reported to increase plasma aldosterone concentrations, resulting in sodium retention. It is unlikely that an aldosterone increase or altered hepatic (cytochrome P450 2D6) metabolism or renal clearance caused the observed cardiac event since the event occured immediately after metoclopramide administration. Elderly are more prone to bradycardia and other cardiovascular events due to, amongst other things, a diminished baroreceptor sensitivity.

\section{Conclusion}

Metoclopramide is known to have a conditional risk of torsades de pointes, meaning it can lead to torsades in certain conditions, whereas domperidone has a known risk of torsades [11]. Because of this lower risk, metoclopramide has been presented as a safe alternative to domperidone. 
Cardiovascular adverse effects are rare but serious. However, given the severity of the cardiac adverse effects, as observed in our patient, we recommend caution and awareness of potential adverse effects when prescribing intravenous metoclopramide, and events should be reported.

\section{Compliance with Ethical Standards}

Funding No financial support was received for the conduct of this study or preparation of this manuscript.

Conflict of interest Laura Sijtsma, Carolina Keijsers, Angèle Kerckhoffs, Willem Agema and Janet Bootsma declare that they have no conflict of interest.

Informed consent Written informed consent was obtained for publication of this case report.

Open Access This article is distributed under the terms of the Creative Commons Attribution-NonCommercial 4.0 International License (http://creativecommons.org/licenses/by-nc/4.0/), which permits any noncommercial use, distribution, and reproduction in any medium, provided you give appropriate credit to the original author(s) and the source, provide a link to the Creative Commons license, and indicate if changes were made.

\section{References}

1. GIP database, Health care institute, the Netherlands. Available at: https://www.gipdatabank.nl/. Accessed Aug 2018.
2. Routledge PA, O’Mahony MS, Woodhouse KW. Adverse drug reactions in elderly patients. Br J Clin Pharmacol. 2014;57:121-6. https://doi.org/10.1046/j.1365-2125.2003.01875.x.

3. European Medicines Agency. Restrictions on the use of domperidone-containing medicines. EMA/465179/2014. London: European Medicines Agency; 2014.

4. SmPC: metoclopramide. Available at: https://www.medicines.org. uk/emc/product/6283/smpc. Accessed Aug 2018.

5. Naranjo CA, Busto U, Sellers EM, Sandor P, Ruiz I, Roberts EA, et al. A method for estimating the probability of adverse drug reactions. Clin Pharmacol Ther. 1981;30(2):239-45.

6. Rumore MM. Cardiovascular adverse effects of metoclopramide: review of literature. Int J Case Rep Images. 2012;3(5):1-10.

7. Grenier Y, Drolet P. Asystolic cardiac arrest: an unusual reaction following iv metoclopramide. Can J Anesth. 2003;50(4):333-5.

8. Bozzi G, Terranova P, Paolino C, Cialfi A, Gandini R, Bevilacqua $M$. The effects of acute administration of metoclopramide on atrial and AV conduction in man. Boll Soc Ital Cardiol. 1981;26:1853-5.

9. Lawson DH, Jick H. Adverse reactions to procainamide. Br J Clin Pharmacol. 1977;4(5):507-11.

10. Gylys JA, Wright RN, Nicolosi WD, Buyniski JP, Crenshaw RR. BMY-25801, an antiemetic agent free of D2-dopamine receptor antagonist properties. J Pharmacol Exp Ther. 1988;244(3):830-7.

11. Woosley RL, Heise CW, Romero KA. QTdrugs List, AZCERT, Inc. Available at www.CredibleMeds.org. Accessed Aug 2018. 